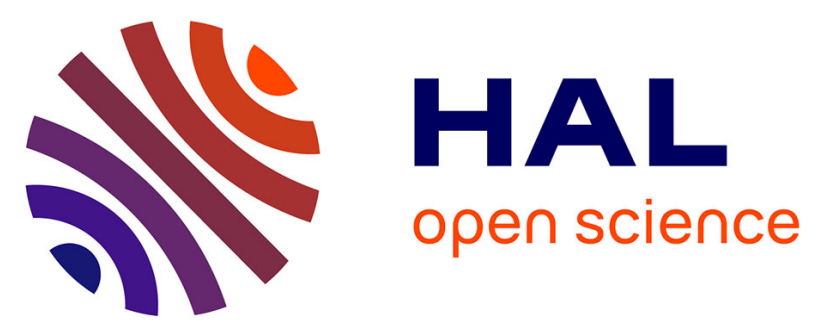

\title{
Pentacoordinated isothiocyanate iron(III) complexes supported by asymmetric tetradentate donor and acceptor Schiff base ligands: Spectral, Structural and Hirshfeld Surface Analyses
}

J. Cisterna, V. Artigas, M. Fuentealba, C. Manzur, Jean-René Hamon, D. Carrillo

\section{To cite this version:}

J. Cisterna, V. Artigas, M. Fuentealba, C. Manzur, Jean-René Hamon, et al.. Pentacoordinated isothiocyanate iron(III) complexes supported by asymmetric tetradentate donor and acceptor Schiff base ligands: Spectral, Structural and Hirshfeld Surface Analyses. Journal of Molecular Structure, 2021, 1230, pp.129864. 10.1016/j.molstruc.2020.129864 . hal-03130432

\author{
HAL Id: hal-03130432 \\ https://hal.science/hal-03130432
}

Submitted on 18 Feb 2021

HAL is a multi-disciplinary open access archive for the deposit and dissemination of scientific research documents, whether they are published or not. The documents may come from teaching and research institutions in France or abroad, or from public or private research centers.
L'archive ouverte pluridisciplinaire HAL, est destinée au dépôt et à la diffusion de documents scientifiques de niveau recherche, publiés ou non, émanant des établissements d'enseignement et de recherche français ou étrangers, des laboratoires publics ou privés. 


\section{HIGHLIGHTS}

- Synthesis of pentacoordinated isothiocyanate-Fe(III)- $\mathrm{N}_{2} \mathrm{O}_{2}$ Schiff base complexes

- Schiff base ligands featuring either a pair of acceptor or donor substituents

- Characterization by elemental analysis, FTIR, UV-vis and HRMS-ESI ${ }^{+}$

- X-ray crystal structure and HSA of the electron poor Fe(III)-NCS complex

- N-bonded NCS ion according to the HSAB concept 
Pentacoordinated isothiocyanate iron(III) complexes supported by asymmetric tetradentate donor and acceptor Schiff base ligands: Spectral, Structural and Hirshfeld Surface Analyses

\author{
Jonathan Cisterna $^{\text {a }}$, Vania Artigas ${ }^{\text {a }}$, Mauricio Fuentealba ${ }^{a}$, \\ Carolina Manzur ${ }^{\mathbf{a}}$, Jean-René Hamon ${ }^{\mathrm{b}}$, David Carrillo ${ }^{\mathbf{a}} *$
}

a Laboratorio de Química Inorgánica and Laboratorio de Cristalografía, Instituto de Química, Facultad de Ciencias, Pontificia Universidad Católica de Valparaíso, Campus Curauma, Avenida Universidad 330, Valparaíso, Chile

b Univ Rennes, CNRS, ISCR (Institut des Sciences Chimiques de Rennes) - UMR 6226, F-35000 Rennes, France

1 Present address: Laboratorio de Química-Física, Departamento de Química, Universidad de Antofagasta: Campus Coloso, Avenida Universidad de Antofagasta 02800, Antofagasta, Chile

This manuscript is dedicated with best wishes to our distinguished colleague Prof. Didier Astruc on the occasion of his $75^{\text {th }}$ birthday, a great friend and scientist who enriched the organometallic, dendrimer, catalysis and nanosciences communities with his fascinating chemistry and amiable personality.

* Corresponding authors.

E-mail addresses: jean-rene.hamon@univ-rennes1.fr (J.-R. Hamon); david.carrillo@pucv.cl

(D. Carrillo). 


\begin{abstract}
The present study aims to synthesis and full characterization of two new pentacoordinated isothiocyanate iron(III) mixed ligand complexes featuring dianionic $\left(\mathrm{N}_{2} \mathrm{O}_{2}\right)^{2-}$ tetradentate Schiff-base ligands unsymmetrically substituted by either a pair of acceptor (4fluorophenyl and nitro) or donor (ferrocenyl and methoxy) substituents. The two neutral complexes 3 and $\mathbf{4}$ were prepared in very good yields ( 90\%) upon reaction of their respective chloro-iron(III) precursors 1 and $\mathbf{2}$ with sodium thiocyanate in refluxing ethanol. The two paramagnetic compounds $\mathbf{3}$ and $\mathbf{4}$ were characterized by elemental analysis, FT-IR and UV-vis spectroscopy, and mass spectrometry. The stretching frequencies of the thiocyanate group observed at 2014 and $2062 \mathrm{~cm}^{-1}$, respectively, indicate a N-bonded NCS moiety, in agreement with the HSAB principle. The crystal structure of 3 revealed that in the five-coordinate monomer, the iron atom adopts a slightly distorted square-pyramidal geometry, with the $\mathrm{N}$ and $\mathrm{O}$ atoms of the Schiff-base ligand occupying the basal sites and the nitrogen atom of the isothiocyanate co-ligand located at the apex of the pyramid. Intermolecular interactions in complex 3 have been addressed with the aid of Hirshfeld surface analysis as well as fingerprint plots. Magnetic susceptibility measurements $(2-300 \mathrm{~K})$ showed a high-spin configuration $(\mathrm{S}=$ $5 / 2$ ) for the $\mathrm{d}^{5} \mathrm{Fe}(\mathrm{III})$ ion in 3.
\end{abstract}

Keywords: iron; isothiocyanate; Schiff base complexes; X-ray crystal structure; ambidentate ligand 


\section{Introduction}

Transition metal complexes of Schiff base ligands have been widely investigated because they can be formed as stable complexes under various coordination geometries and oxidation states [1-5]. They have found a plethora of applications in various branches of science [6], such as, for instance, in catalysis [7,8], molecular magnetism [9,10], as nonlinear optics (NLO) molecular materials [11-13], and for their remarkable bioactivity [14-16]. Schiff base complexes have also been used as molecular building blocks in the development of multimetalic and new materials $[17,18]$. In particular, the design and synthesis of iron complexes with Schiff base ligands play a major role in the coordination chemistry of this earth abundant and biocompatible element. Indeed, inherent potentials of these complexes are their importance as biomimetic functional models for iron-containing enzymes [19,20], in medicinal chemistry [21-23], as catalysts [24-26], and as molecular materials based on spin crossover behavior [27-30]. On the other hand, both divalent and trivalent iron complexes of tetradentate Schiff base ligands have been taken under consideration since they exhibit unique coordination chemistry. Complexation of $\mathrm{Fe}(\mathrm{III})$ ions to diprotic Schiff base proligands having $\left[\mathrm{N}_{2} \mathrm{O}_{2}\right]$ core generates a platform from which mixed-ligand species can be built up in presence of various co-ligands (halides, pseudohalides, solvent molecules or N-containing heterocycles) [31-34]. Depending on the lability of the co-ligands, such mixed-ligand complexes could serve as potential precursors for the construction of more sophisticated structures. Among the pseudo-halides, the $\mathrm{NCS}^{-}$thiocyanate anion is an incredibly versatile ambidentate ligand with two donor atoms [35], known to coordinate to metal ions in both terminal and bridging modes. The sulfur and nitrogen ends are soft and hard type bases, respectively [36]. The $\mathrm{NCS}^{-}$anion can be bonded to a metal ion either through the $\mathrm{N}$ atom ( $\mathrm{M}-\mathrm{N}=\mathrm{C}=\mathrm{S}$, isothiocyanate) or the $\mathrm{S}$ atom (M-S-C $\equiv \mathrm{N}$, thiocyanate), depending on the nature of the metal and/or of the ancillary ligands, giving rise to linkage isomers [37,38]. It can also readily bridge different metal ions through its terminal donor atoms, forming double $\mu^{1,3}$-thiocyanato bridged dimers [39-41], or one-dimensional polynuclear complexes [M-NCS-M $]_{\mathrm{n}}$ [42,43]. An uncommon dinuclear Fe(II) complex featuring both end-toend bridging and terminal thiocyanato ligand has also recently been described [44]. Hard acids $\mathrm{Fe}(\mathrm{II})$ and $\mathrm{Fe}$ (III) ions, like other first-row transition metals, form the isothiocyanate isomer by way of M-NCS coordination [45,46], generating a stable «hard-hard» Fe-N interaction $[35,36]$. Thus, insertion of N-bound $\mathrm{NCS}^{-}$co-ligand in the coordination sphere of the iron(III) center of 
the Schiff base complexes leads to the formation of mostly mononuclear six-coordinate iron(III) [Fe( $\left.\left(\mathrm{N}_{2} \mathrm{O}_{2}\right)(\mathrm{L})(\mathrm{NCS})\right]$-type compounds [33,47-51], while reported corresponding five-coordinate $\mathrm{Fe}(\mathrm{III})$ derivatives $\left[\mathrm{Fe}\left(\mathrm{N}_{2} \mathrm{O}_{2}\right)(\mathrm{NCS})\right]$ are scarce [47,52]. Beneficially, the free sulfur atom allows the anchoring of the metal complex on gold nanoparticles [53].

Herein we report on the synthesis and full characterization of two new neutral pentacoordinate iron(III) complexes featuring unsymmetric tetradentate Schiff base ligands substituted by either a pair of acceptor $\left(\mathrm{L}^{\mathrm{A}}\right.$ : 4-fluorophenyl/nitro) or donor $\left(\mathrm{L}^{\mathrm{D}}\right.$ : ferrocenyl [54]/methoxy) groups, with terminal N-coordinated isothiocyanato co-ligand. Both mixed-ligand complexes of the type $\left[\mathrm{Fe}\left(\mathrm{L}^{\mathrm{A}} / \mathrm{L}^{\mathrm{D}}\right)(\mathrm{NCS})\right] \mathbf{3}$ and $\mathbf{4}$, respectively, were prepared starting from their previously reported corresponding pentacoordinated chloro iron(III) precursors 1 and 2 [55], upon reaction with sodium thiocyanate (see formulas in Scheme 1). Complex $\mathbf{3}$ was structurally characterized. The existence of intermolecular interactions is supported by Hirshfeld surface analysis and quantified by 2D fingerprint plots [56,57]. Magnetic investigations revealed that 3 stays in the high-spin (HS) state over the whole temperature range.

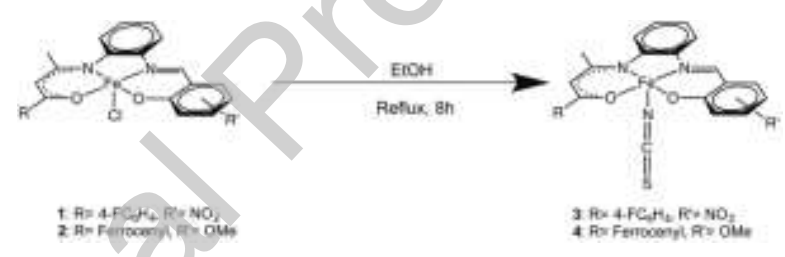

Scheme 1 Synthesis of the isothiocyanate-iron(III) Schiff base complexes $\mathbf{3}$ and $\mathbf{4}$.

\section{Experimental Section}

\subsection{Materials and physical measurements}

All manipulations were performed under dry nitrogen atmosphere using standard Schlenk techniques. Solvents were dried and distilled according to standard procedures [58]. Reagents were purchased from commercial suppliers and used without further purification. The chloroiron(III) precursors 1 and 2 were synthesized according to the published procedure [55]. Solidstate FT-IR spectra were recorded on a Perkin-Elmer Model 1600 FT-IR spectrophotometer with $\mathrm{KBr}$ disks in the 4000 to $450 \mathrm{~cm}^{-1}$ range. Electronic spectra were obtained with a Thermo Scientific Model Helios Omega 76006 v8.0 spectrophotometer. High resolution electrospray ionization mass spectra (HRMS-ESI ${ }^{+}$) were conducted on a Bruker MAXI 4G or Thermo Fisher 
Scientific Q-Exactive mass spectrometer in positive mode, at the Centre Régional de Mesures Physiques de 1'Ouest (CRMPO, Université de Rennes 1, France). Elemental analyses were carried out on a Thermo-Finnigan Flash EA 1112 CHNS/O analyzer by the Microanalytical Service of the CRMPO. The temperature dependences of the magnetizations for powdered samples have been measured with a SQUID magnetometer (Quantum design MPMS-XL5) operating between 2 and $300 \mathrm{~K}$ at a constant field of $2 \mathrm{k} \emptyset \mathrm{e}$ below $20 \mathrm{~K}$ and $10 \mathrm{k} \emptyset \mathrm{e}$ above. The experimental data have been corrected from the sample holder diamagnetism and the intrinsic diamagnetism estimated from the Pascal's tables [59]. Melting points were determined in evacuated capillaries on a Kofler Bristoline melting point apparatus and were not corrected.

\subsection{Synthesis of the isothiocyanate complex 3}

A Schlenk tube containing a magnetic stirring bar was charged with $300 \mathrm{mg}(0.590 \mathrm{mmol} ; 1$ equiv) of precursor 1 and $292 \mathrm{mg}$ (3.60 mmol; 3 equiv) of sodium thiocyanate. Ethanol (10 mL) was then added and the reaction mixture refluxed for $8 \mathrm{~h}$. Upon cooling to room temperature, the solvent was evaporated under reduced pressure, and the residue extracted with dichloromethane. The extracts were combined and evaporated to dryness under vacuum. Yield: $287 \mathrm{mg}$ (93\%) of a microcrystalline dark brown solid. Recrystallization by slow diffusion of diethyl ether into a saturated dichloromethane solution of the complex afforded black single crystals suitable for Xray structure determination. M.p. $166-168 \quad{ }^{\circ} \mathrm{C}$. Anal. calcd for $\mathrm{C}_{24} \mathrm{H}_{16} \mathrm{FFeN} \mathrm{O}_{4} \mathrm{~S} \cdot \mathrm{C}_{2} \mathrm{H}_{5} \mathrm{OH} \cdot 0.8 \mathrm{CH}_{2} \mathrm{Cl}_{2}\left(645.31 \mathrm{~g} \mathrm{~mol}^{-1}\right): \mathrm{C}, 49.88 ; \mathrm{H}, 3.69 ; \mathrm{N}, 8.68 ; \mathrm{S}, 4.97$. Found: C, 49.93; H, 3.62; N, 8.69; S, 5.17. ESI MS (m/z) calcd for $\mathrm{C}_{23} \mathrm{H}_{16} \mathrm{~N}_{3} \mathrm{O}_{4} \mathrm{~F}^{56} \mathrm{Fe}[\mathrm{M}-$ $\mathrm{SCN}^{+}$: 473.04687, found: 473.0475; calcd for $\mathrm{C}_{47} \mathrm{H}_{32} \mathrm{~N}_{7} \mathrm{O}_{8} \mathrm{~F}_{2} \mathrm{~S}^{56} \mathrm{Fe}_{2}$ [2M-.SCN] $]^{+}$: 1004.06944, found: 1004.0711. FT-IR (KBr pellet, $\left.\mathrm{cm}^{-1}\right): 2014$ (vs) $v(\mathrm{NCS}), 1606(\mathrm{~s}) v(\mathrm{C}-\mathrm{N}), 1560$ (w), 1546 $(\mathrm{s}), 1492(\mathrm{~s}) v_{\text {asym }}(\mathrm{N} \cdots \mathrm{O}), 1320(\mathrm{~s}) v_{\text {sym }}(\mathrm{N} \cdots \mathrm{O}), 1100 \mathrm{~m} v(\mathrm{C}-\mathrm{F})$.

\subsection{Synthesis of the isothiocyanate complex 4}

The synthesis of the dark brown microcrystalline solid $\mathbf{4}$ is similar to that described above for $\mathbf{3}$, using in this case $300 \mathrm{mg}(0.514 \mathrm{mmol})$ of the precursor 2 and $250 \mathrm{mg}(3.08 \mathrm{mmol})$ of sodium thiocyanate. Yield: $278.6 \mathrm{mg}(89.4 \%)$. Repeated attempts to grow suitable X-ray single crystal of complex 4 only resulted in powders. M.p. 143-145 ${ }^{\circ} \mathrm{C}$. Anal. Calcd for $\mathrm{C}_{29} \mathrm{H}_{24} \mathrm{Fe}_{2} \mathrm{~N}_{3} \mathrm{O}_{3} \mathrm{~S} \cdot 0.8\left(\mathrm{C}_{2} \mathrm{H}_{5}\right)_{2} \mathrm{O}\left(665.2 \mathrm{~g} \mathrm{~mol}^{-1}\right): \mathrm{C}, 58.09 ; \mathrm{H}, 4.81 ; \mathrm{N}, 6.31 ; \mathrm{S}, 4.81$. Found: $\mathrm{C}$, 58.46; H, 4.51; N, 6.92; S, 4.03. ESI MS (m/z) calcd for $\mathrm{C}_{29} \mathrm{H}_{24} \mathrm{~N}_{3} \mathrm{O}_{3} \mathrm{~S}^{56} \mathrm{Fe}_{2}[\mathrm{M}]^{+}: 606.02317$, found: 606.0235; calcd for $\mathrm{C}_{28} \mathrm{H}_{24} \mathrm{~N}_{2} \mathrm{O}_{3}{ }^{56} \mathrm{Fe}_{2}$ [M - SCN] ${ }^{+}$: 548.04802, found: 548.0483. FT-IR 
$\left(\mathrm{KBr}\right.$ pellet, $\left.\mathrm{cm}^{-1}\right): 3100(\mathrm{w}), 3062$ (w), $2960 v(\mathrm{C}-\mathrm{H}$ arom), 2924 (w), 2850 (vw), 2834 (m) v(C-H aliph), 2062 (vs) $v(\mathrm{NCS}), 1616(\mathrm{~m}) v\left(\mathrm{C}^{\cdots} \mathrm{N}\right), 1560$ (s), 1534 (s) 1324 (m) $v(\mathrm{C}-\mathrm{O})$.

\subsection{X-Ray crystal structure determination}

A clear dark red block -shaped crystal of $\mathbf{3}$ was mounted on top of glass fibers in a random orientation. Intensity diffraction data were collected at 296(2) K on a Bruker D8 QUEST diffractometer equipped with a bidimensional CMOS Photon100 detector, using graphite monochromated Mo-K $\alpha$ radiation $(\lambda=0.71073 \AA)$. The diffraction frames were integrated using the APEX3 package [60], and were corrected for absorptions with SADABS. The structure of 3 was solved with the SHELXS [61] structure solution program by Direct Methods and refined with the SHELXL [ES5] refinement package by Least Squares minimization using the OLEX2 program [62]. Non-hydrogen atoms were refined with anisotropic displacement parameters. All hydrogen atoms were included in their calculated positions, assigned fixed isotropic thermal parameters and constrained to ride on their parent atoms. Disordered dichloromethane solvate molecule was modelled using solvent mask [63] and BYPASS routine [64]. A summary of the details about crystal data, collection parameters and refinement are documented in Table 1, and additional crystallographic details are in the CIF file. ORTEP views were drawn using OLEX2 software [62]. 
Table 1 Crystal data, details of data collection and structure refinement parameters for complex 3.

\begin{tabular}{|c|c|}
\hline Parameters & 3 \\
\hline Empirical Formula & $\mathrm{C}_{24} \mathrm{H}_{16} \mathrm{FFeN}_{4} \mathrm{O}_{4} \mathrm{~S}$ \\
\hline Formula mass, $\mathrm{g} \mathrm{mol}^{-1}$ & 531.32 \\
\hline Collection $\mathrm{T}, \mathrm{K}$ & $296(2)$ \\
\hline crystal system & Triclinic \\
\hline space group & $\mathrm{P} \overline{1}$ \\
\hline$a(\AA)$ & $9.1888(10)$ \\
\hline $\mathrm{b}(\AA)$ & $11.6471(11)$ \\
\hline$c(\AA)$ & $12.6569(13)$ \\
\hline$\alpha\left(^{\circ}\right)$ & $81.139(5)$ \\
\hline$\beta\left(^{\circ}\right)$ & $88.273(5)$ \\
\hline$\gamma\left({ }^{\circ}\right)$ & $84.456(5)$ \\
\hline $\mathrm{V}\left(\AA^{3}\right)$ & $1332.0(2)$ \\
\hline $\mathrm{Z}$ & $2 \times(>-2$ \\
\hline $\mathrm{D}_{\text {calcd }}\left(\mathrm{g} \mathrm{cm}^{-3}\right)$ & 1.325 \\
\hline Crystal size (mm) & $0.300 \times 0.228 \times 0.222$ \\
\hline $\mathrm{F}(000)$ & 542.0 \\
\hline abs coeff $\left(\mathrm{mm}^{-1}\right)$ & 0.686 \\
\hline$\theta$ range $\left(^{\circ}\right)$ & 2.221 to 26.460 \\
\hline range $\mathrm{h}, \mathrm{k}, \mathrm{l}$ & $-11 / 11,-14 / 14,-15 / 15$ \\
\hline No. total refl. & 69823 \\
\hline No. unique refl. & 5496 \\
\hline Comp. $\theta_{\max }(\%)$ & 99.9 \\
\hline Max/min transmission & $0.9153 / 0.8563$ \\
\hline Data/Restraints/Parameters & $5496 / 0 / 317$ \\
\hline Final $R[I>2 \sigma(I)]$ & $\mathrm{R}_{1}=0.0448, \mathrm{wR}_{2}=0.1168$ \\
\hline $\mathrm{R}$ indices (all data) & $\mathrm{R}_{1}=0.0583, \mathrm{wR}_{2}=0.1287$ \\
\hline Goodness of fit / $\mathrm{F}^{2}$ & 1.038 \\
\hline Largest diff. Peak/hole $\left(\mathrm{e}^{-3}{ }^{-3}\right)$ & $0.722 /-0.811$ \\
\hline
\end{tabular}

\subsection{Hirshfeld surface analysis}

CrystalExplorer 17.5 software [65] was used to calculate Hirshfeld surface [66,67] and associated 2D-fingerprint plots $[68,69]$ of complex $\mathbf{3}$, using the crystallographic information file (CIF) as input for the analysis. The normalized contact distance $d_{n o r m}$, defined in terms of $d_{e}, d_{i}$ and vdW raddi of the atoms, was calculated using Eq. 1, where $d_{e}$ and $d_{i}$ are the distance from the Hirshfeld isosurface to the nearest external and internal nucleus, respectively, and vdW is the van der Waals raddi of atoms taken from the literature [70]. 


$$
d_{\text {norm }}=\frac{d_{\mathrm{i}}-r_{\mathrm{i}}^{\mathrm{vdW}}}{r_{\mathrm{i}}^{\mathrm{vdW}}}+\frac{d_{\mathrm{e}}-r_{\mathrm{e}}^{\mathrm{vdW}}}{r_{\mathrm{e}}^{\mathrm{vdW}}}
$$

\section{Eq. 1}

The electrostatic potentials were mapped on the Hirshfeld surfaces [71], using the 6$31 \mathrm{G}(\mathrm{d}, \mathrm{p})$ basis set [72] at B3LYP level of theory [73] over a range of $\pm 0.002 \mathrm{au}$. For the generation of fingerprint plots the bond lengths of hydrogen atoms involved in interactions were normalized to standard neutron values $(\mathrm{C}-\mathrm{H}=1.083 \AA$, N-H $=1.009 \AA, \mathrm{O}-\mathrm{H}=0.983 \AA$ ) [74]. The intermolecular energies of the molecular pairs in the crystal packing were calculated, at B3LYP/6-31G(d,p) level of theory, in cluster of radius $3.8 \AA$ around the molecule [69].

\section{Results and discussion}

\subsection{Synthesis and characterization}

The neutral iron(III) complexes 3 and 4 were readily prepared by reacting their known corresponding chloro-Fe(III) precursors 1 and 2 [55] with sodium thiocyanate in refluxing ethanol for $8 \mathrm{~h}$. A simple scheme showing the synthesis of the two complexes is depicted in Scheme 1. Both complexes were isolated in excellent yields (> $80 \%)$ as dark brown microcrystalline solids. They are stable under air and moisture, exhibit good solubility in polar organic solvents such as ethanol, dichloromethane, acetonitrile and dimethylsulfoxide (DMSO), but are insoluble in diethyl ether and hydrocarbons.

The isolated complexes were characterized by satisfactory elemental analysis, FT-IR and UV-vis spectroscopy, magnetic measurements, and by single-crystal X-ray crystallography and Hirshfeld Surface analysis in the case of $\mathbf{3}$. In addition, both MS-ESI ${ }^{+}$spectra of $\mathbf{3}$ and $\mathbf{4}$ are dominated by the ion peak $[\mathrm{M}-\mathrm{SCN}]^{+}$at $\mathrm{m} / \mathrm{z}=473$ and 548 , respectively. However, the molecular ion peak at $\mathrm{m} / \mathrm{z}=606[\mathrm{M}]^{+}(10 \%)$ is also observed in the spectrum of $\mathbf{4}$, while for 3 the presence of the NCS fragment is confirmed by the peak at $\mathrm{m} / \mathrm{z}=1004$, corresponding to the $[2 \mathrm{M}-(\mathrm{SCN})]^{+}$ion (see sections 2.2 and 2.3 for details). 


\subsection{Infrared spectroscopy}

The solid-state FT-IR spectra of complexes $\mathbf{3}$ and $\mathbf{4}$ show a quite similar absorption band pattern to that of their chloro-iron(III) precursors 1 and 2, respectively (see Figs S1 and S2), suggesting the analogy of their molecular structures [55]. Both spectra present the characteristic strong $v(C=N)$ stretching vibration of the azomethine group at 1606 and $1616 \mathrm{~cm}^{-1}$, respectively. The lowering of the positions of these bands indicates the coordination of the imine nitrogen to the metal centers [55]. Two strong bands at 1492 and $1320 \mathrm{~cm}^{-1}$, due to the asymmetric and symmetric vibrational modes of the nitro substituent, are additionally seen in the spectrum of $\mathbf{3}$ (Fig. 1) [75]. Besides, the strong sharp absorption bands at 2014 and $2062 \mathrm{~cm}^{-1}$ observed in the spectra of 3 and 4, respectively (Figs. 1 and S2), correspond to the thiocyanate group stretching frequencies [76]. In the case of $\mathbf{3}$, the band at $2014 \mathrm{~cm}^{-1}$ is confidently attributed to the asymmetric stretching vibration of the $\mathrm{N}$-bonded terminal $\mathrm{SCN}^{-}$moiety as ascertained from the X-ray diffraction study (see section 3.3 below). The situation is less straightforward for complex 4 for which no crystal structure is available. However, based on previous observations [33,46-51] and despite the increase of electron density brought about by the two donor substituents that could increase the polarisability of the iron(III) center [36], the strong stretching vibration observed at $2062 \mathrm{~cm}^{-1}$ in the spectrum of 4 (Fig. S2) could also be confidently assigned to the $\mathrm{SCN}^{-}$co-ligand bound via its nitrogen atom to the iron(III) ion. Moreover, the steric hindrance of the ferrocenyl substituent might disfavor the formation of a bent Fe-SCN coordination mode. The Fe-NCS way of coordination in both $\mathbf{3}$ and $\mathbf{4}$ can be explained using the hard-soft acid-base (HSAB) Principle [36]. Indeed, during the ligand exchange reaction, the axial chlorido ligand of $\mathbf{1}$ and $\mathbf{2}$ is substituted with the thiocyanate anion to form the pentacoordinated isothiocyanateiron(III) counterparts 3 and 4, respectively, in which the $\mathrm{SCN}^{-}$group is coordinated to the iron(III) metal center (a hard acid) through the nitrogen atom (a hard base). 


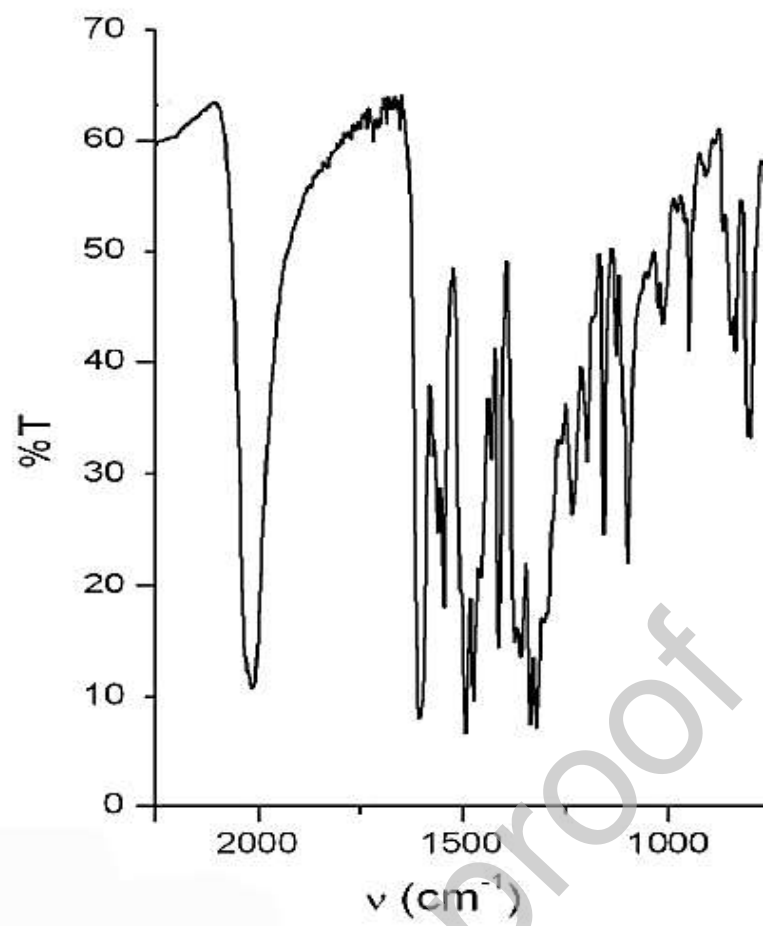

Fig. 1 FT-IR spectrum of the isothiocyanate-iron(III) complex 3 in the $2150-1000 \mathrm{~cm}^{-1}$ range.

\subsection{Description of the $X$-ray crystal structure of 3}

The molecular structure along with numbering scheme for selected atoms of complex $\mathbf{3}$ is shown in Fig. 2. Bond lengths and angles for the first iron(III) coordination sphere are provided in Table 2, whereas the other relevant bond distances and angles are gathered in Table S1 (Supplementary Material). Complex $\mathbf{3}$ crystallizes in the triclinic centrosymmetric space group $\mathrm{P} \overline{\mathbf{1}}$ with one molecule per asymmetric unit. It is a mononuclear Fe(III) compound in which the iron center has a distorted five-coordinate geometry. The ferric ion is coordinated to a tetradentate unsymmetrically-substituted electron-withdrawing $\mathrm{N}_{2} \mathrm{O}_{2}$ Schiff base framework that constitues the basal plane. The axial site is filled with one thiocyanate ion as terminal ligand, finishing its coordination polyhedron (Fig. 2). The structure of compound $\mathbf{3}$ is reminiscent of that of its pentacoordinated chlorido precursor $\mathbf{1}$ [55], and to the best of our knowledge, $\mathbf{3}$ is the first pentacoordinated isothiocyanate iron(III) complex featuring a salen/salphen-type core to be structurally characterized. 


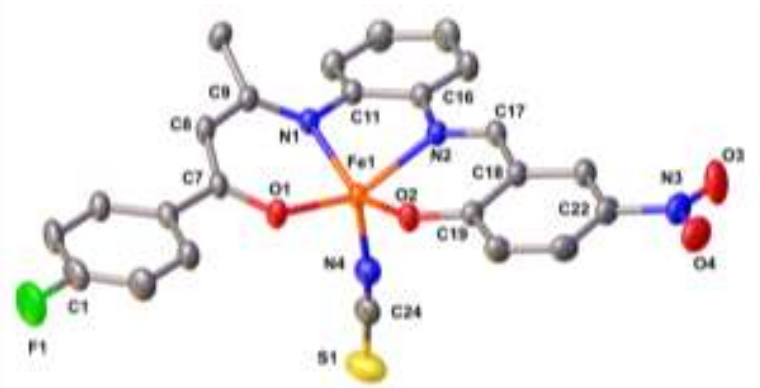

Fig. 2 Molecular structure of complex 3 with numbering scheme for selected atoms. Hydrogen atom are omitted for clarity. Thermal ellipsoids are drawn at $30 \%$ probability level.

The iron(III) ion adopts a square pyramidal geometry (trigonality index $t=0.11 ; t=0$ for square pyramid and 1 for trigonal bipyramid) [77] with a $\mathrm{FeN}_{3} \mathrm{O}_{2}$ chromophore. The iron atom is displaced by $0.523 \AA$ from the least-squares plane (LSP) defined by the Schiff-base donor atoms. Thus, complex 3 appears to be less distorted than its chloro-iron(III) precursor $\mathbf{1}\left(\tau=0.32, \mathrm{~d}_{\mathrm{Fe}-\mathrm{LSP}}\right.$ $=0.529 \AA$ ) [55]. Out of its five coordination sites, four positions are occupied by the dianionic tetradentate Schiff base ligand through two nitrogen (amino and imino) atoms and two oxygen (carbonyl and phenolato) atoms. The remaining fifth coordination position is satisfied by a thiocyanate moiety which is linked to the Fe(III) ion through a terminal nitrogen atom with a $\mathrm{Fe}(1)-\mathrm{N}(4)$ bond length of 1.964(3) $\AA$ and a Fe(1)-N(4)-C(24) angle close to linearity [172.3(3) ${ }^{\circ}$. The isothiocyanate group, which acts as a monodentate ligand, is linear within the experimental error $\left.[\mathrm{N}(4)-\mathrm{C}(24)-\mathrm{S} 1)=178.2(3)^{\circ}\right]$. The iron-isothiocyanate $\mathrm{Fe}-\mathrm{N}$ bond distance is slightly shorter than those measured in both neutral six-coordinate $\mathrm{Fe}$ (III) derivatives $\left[\mathrm{Fe}\left(\mathrm{N}_{2} \mathrm{O}_{2}\right)(\mathrm{L})(\mathrm{NCS})\right]\left(\mathrm{d}_{\mathrm{Fe}-\mathrm{N}}=2.02-2.05 \AA\right) \quad[33,49,51]$, and anionic five-coordinate $\mathrm{Fe}(\mathrm{II})$ complexes $\left[\mathrm{Fe}\left(\mathrm{N}_{2} \mathrm{O}_{2}\right)(\mathrm{NCS})\right]^{-}\left(\mathrm{d}_{\mathrm{Fe}-\mathrm{N}}=2.05 \AA\right)$ [45]. The Fe-N-C and NCS angles found in 3 (Table 2) are similar to those measured for both $\mathrm{Fe}$ (II) and Fe(III) compounds. Moreover, the $\mathrm{Fe}(1)-\mathrm{O}(1), \mathrm{Fe}(1)-\mathrm{O}(2), \mathrm{Fe}(1)-\mathrm{N}(1)$ and $\mathrm{Fe}(1)-\mathrm{N}(2)$ bond lengths of 3 (Table 2) are almost identical to their respective ones in the chloro-iron(III) precursor 1 [55]. However, the Fe-N bond distances of 2.0622(19) and 2.090(2) $\AA$, similar to those observed in the pentacoordinated isothiocyanate-iron(II) species [45] but shorter than those found in the pseudo-octahedral 
counterparts $[33,49,51]$, clearly suggest that the iron(III) ion is in the high-spin state, and this matches the magnetic data (see section 3.6 below).

Coordination of the tetradentate Schiff base ligand forms one five-membered and a pair of six-membered chelate rings with the central Fe(III) metal ion. The respective chelate bite angles are $77.86(7)^{\circ}, 86.49(7)^{\circ}$ and $89.09(8)^{\circ}$ (Table 2). The two O-Fe-N angles are about $150^{\circ}$ (Table 2 ), and the planes of the [O-C-C-C-N] chelate rings make a dihedral angle of $33.39(11)^{\circ}$. This reflects the strain exerted by the ligand structure and results in a significantly bent arrangement of the ligand. Lastly, the $[\mathrm{O}(1)-\mathrm{C}(7)-\mathrm{C}(8)-\mathrm{C}(9)-\mathrm{N}(1)]$ plane makes a dihedral angle of $22.78(11)^{\circ}$ with that of its 4-fluorophenyl substituent. The $\mathrm{NO}_{2}$ group is almost coplanar $\left(9.45(13)^{\circ}\right)$ with the salicylidene ring. Those values are respectively smaller by $22^{\circ}$ and larger by $5^{\circ}$ with respect to the corresponding ones found in the chloro-iron(III) precursor 1 [55].

Table 2 Selected bond distances $(\AA)$ and angles $\left(^{\circ}\right)$ for the first Fe(III) coordination sphere of compound 3 .

\begin{tabular}{llll}
\hline \multicolumn{4}{c}{ Bond lengths } \\
\hline $\mathrm{Fe}(1)-\mathrm{O}(1)$ & $1.8988(17)$ & $\mathrm{Fe}(1)-\mathrm{O}(2)$ & $1.9069(17)$ \\
$\mathrm{Fe}(1)-\mathrm{N}(1)$ & $2.0622(19)$ & $\mathrm{Fe}(1)-\mathrm{N}(2)$ & $2.090(2)$ \\
$\mathrm{Fe}(1)-\mathrm{N}(4)$ & $1.964(3)$ & $\mathrm{N}(4)-\mathrm{C}(24)$ & $1.118(4)$ \\
$\mathrm{S}(1)-\mathrm{C}(24)$ & $1.615(4)$ & & \\
\hline & \multicolumn{1}{c}{$\mathrm{B}$. } \\
$\mathrm{O}(1)-\mathrm{Fe}(1)-\mathrm{N}(2)$ & $151.81(9)$ & $\mathrm{O}(2)-\mathrm{Fe}(1)-\mathrm{N}(1)$ & $145.43(9)$ \\
$\mathrm{O}(1)-\mathrm{Fe}(1)-\mathrm{N}(1)$ & $89.09(8)$ & $\mathrm{O}(2)-\mathrm{Fe}(1)-\mathrm{O}(1)$ & $90.65(8)$ \\
$\mathrm{N}(1)-\mathrm{Fe}(1)-\mathrm{N}(2)$ & $77.86(7)$ & $\mathrm{O}(2)-\mathrm{Fe}(1)-\mathrm{N}(2)$ & $86.49(7)$ \\
$\mathrm{N}(4)-\mathrm{Fe}(1)-\mathrm{O}(1)$ & $105.34(10)$ & $\mathrm{N}(4)-\mathrm{Fe}(1)-\mathrm{O}(2)$ & $107.30(10)$ \\
$\mathrm{N}(4)-\mathrm{Fe}(1)-\mathrm{N}(1)$ & $106.07(9)$ & $\mathrm{N}(4)-\mathrm{Fe}(1)-\mathrm{N}(2)$ & $102.27(9)$ \\
$\mathrm{Fe}(1)-\mathrm{N}(4)-\mathrm{C}(24)$ & $172.3(3)$ & $\mathrm{N}(4)-\mathrm{C}(24)-\mathrm{S}(1)$ & $178.2(3)$ \\
\hline
\end{tabular}

\subsection{Hirshfeld surface analysis}

Hirshfeld surface analysis $[56,57,67]$ was carried out to verify the contributions of the different intermolecular interactions of compound $\mathbf{3}$ in the crystal structure (Fig. 3), where these 
interactions are mainly constituted by $\mathrm{C}-\mathrm{H} \cdots \mathrm{C}, \mathrm{C}-\mathrm{H} \cdots \mathrm{N}$ and $\mathrm{C}-\mathrm{H} \cdots \mathrm{O}$, in a centrosymmetric setting in the crystal structure. Other weak interactions were confirmed with complementary analyses with shape index and curvedness surface.
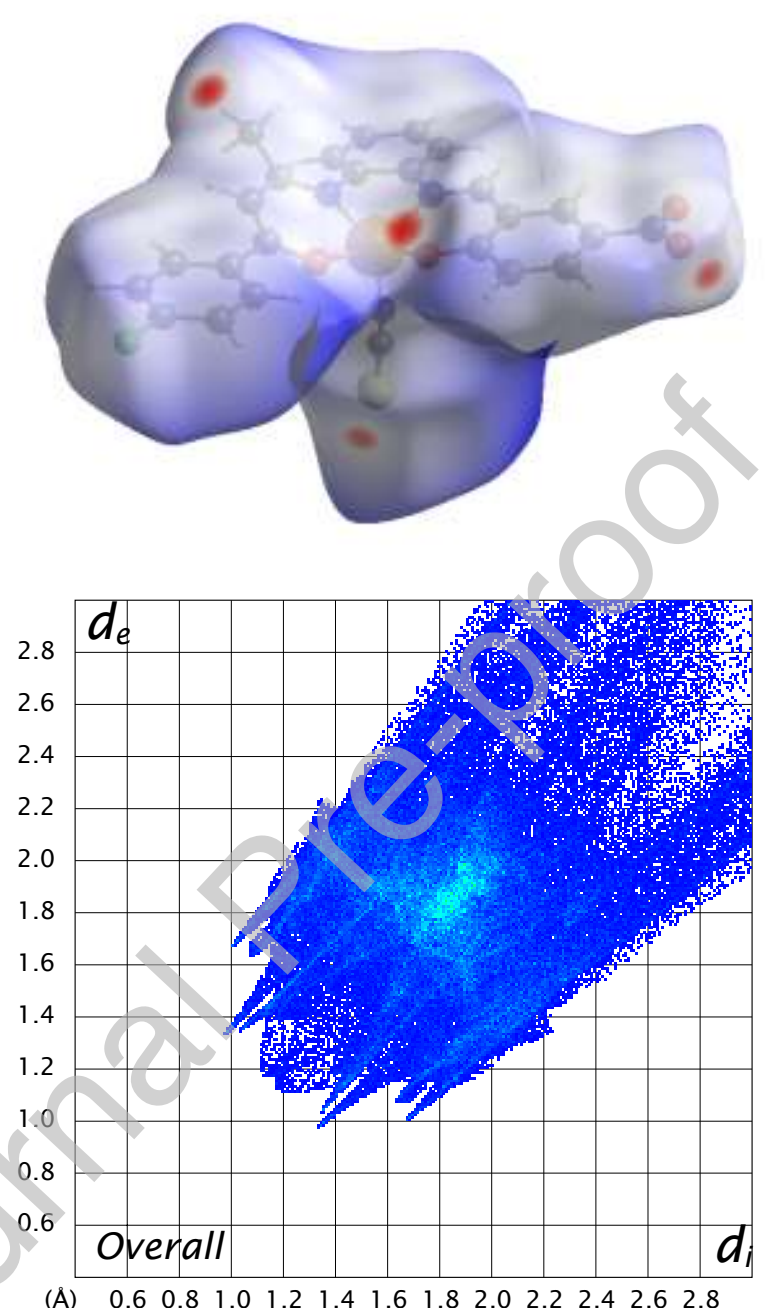

Fig. $3 d_{\text {norm }}$ Hirshfeld surface over molecular structure of compound $\mathbf{3}$ (top) and its full fingerprint plot (bottom).

The reciprocal contacts for $\mathrm{C}-\mathrm{H} \cdots \mathrm{C}$ and $\mathrm{C}-\mathrm{H} \cdots \mathrm{N}$, appear as a broad symmetrical wing with $d_{\mathrm{e}}+$ $d_{i} \simeq 2.8 \AA$, corresponding to $\mathrm{C}-\mathrm{H} \cdots \pi$ weak interactions. In the latter, the distance is slightly greater than the VdW radii for $\mathrm{N}$ and $\mathrm{H}$ atoms $\left(d_{\mathrm{e}}+d_{i}<2.75 \AA\right)$. For $\mathrm{C}-\mathrm{H} \cdots \mathrm{O}$ symmetrical closed clamps with $d_{\mathrm{e}}+d_{i} \simeq 2.4 \AA$ (see Fig. S3 for more details). The interatomic contacts of $\mathrm{C}-$ 
$\mathrm{H} \cdots \mathrm{H}$ interactions show a $d_{i}+d_{e} \simeq 2.3 \AA<2.4 \AA$, denoting $\mathrm{H} \cdots \mathrm{H}$ short contacts with another significant effect on the molecular packing with a contribution around $18 \%$. Another type of weak interactions is also observed in the Hirshfeld Surface analysis. For example, the contribution of $\mathrm{C} \cdots \mathrm{C}\left(\pi \cdots \pi\right.$ type interaction) are around $5.9 \%$, when $d_{\mathrm{e}}+d_{i}$ of $\sim 3.8$ $\AA$, with a lesser contribution of $6.4 \%$, respectively. This last weak interaction is observed between two $o$-phenylene ring of neighboring molecules and two 4-fluorophenyl moieties between neighboring molecules being part of centrosymmetric setting in the crystal structure (Fig. 4).

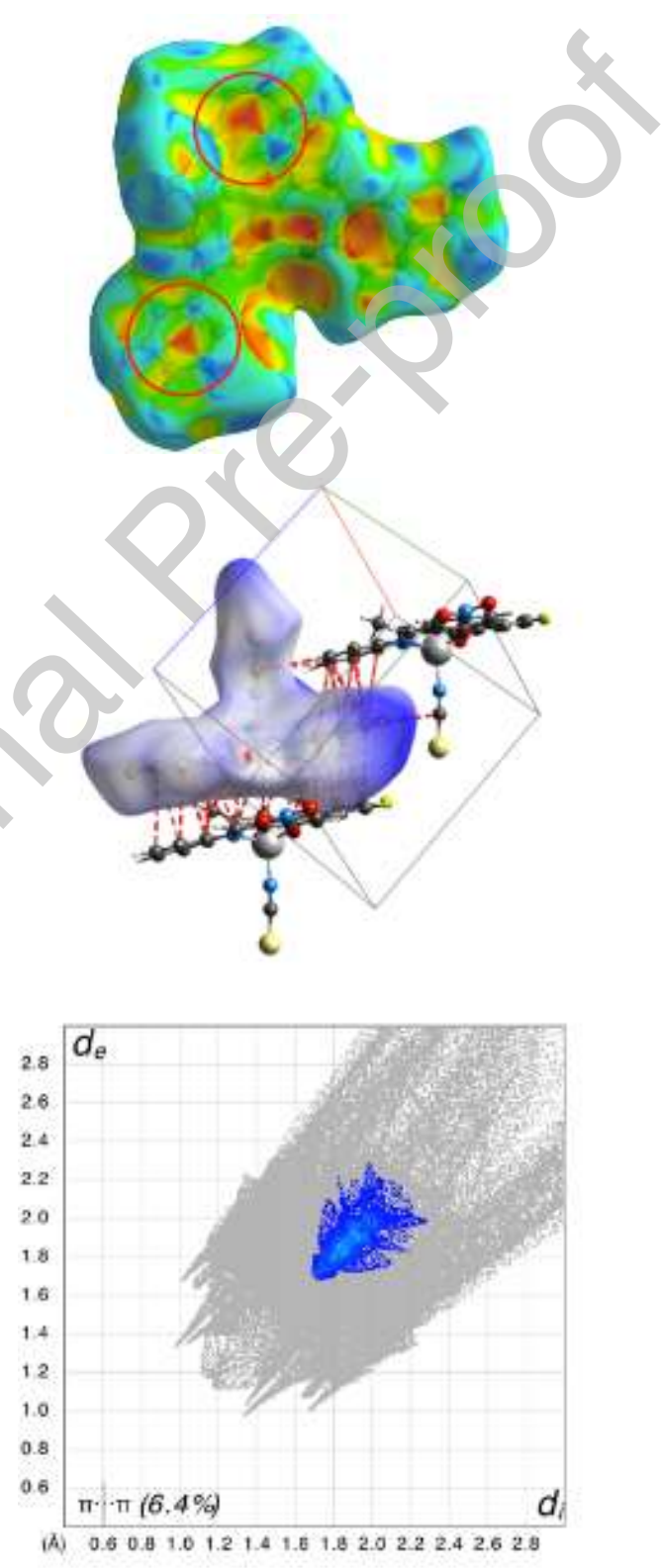


Fig. 4 Shape index (top), interatomic interactions (center) and fingerprint plot (bottom) of compound $\mathbf{3}$, showing the $\mathrm{C} \cdots \mathrm{C}$ contacts.

Finally, energy framework was analysed for a better understanding of the packing and topology of the crystal structure and the supramolecular rearrangement (Fig. S4). According to the total intermolecular contacts contribution, the supramolecular structure of this compound generate an antiparalell one dimensional chain along the $a$-axis. The tube direction of the energy framework allows to conclude that the formation of crystal structure is directed just by centrosymmetry elements, specifically an inversion center. This rearrangement allows the formation of another weak interactions in the crystal structure. The results of the calculations revealed that dispersion interactions exhibit approximately ladder shape energy topologies. The small value of electrostatic energy versus dispersion energy in compound $\mathbf{3}$ is attributed to the absence or few classical hydrogen bonds interactions, despite of several number of interactions in the crystal packing (see Table S2 for more details).

\subsection{Electronic absorption spectroscopy}

UV-vis absorption spectra of complexes 3 and $\mathbf{4}$ were recorded in $\mathrm{CH}_{2} \mathrm{Cl}_{2}$ medium at room temperature in the range 200-800 $\mathrm{nm}$. Both experimental and deconvoluted spectra are displayed in Fig. 5. The deconvoluted spectral data are collected in Table 3. The high-energy bands in the range $248-342 \mathrm{~nm}$ were attributed to intra-ligand $\pi-\pi^{*} / \mathrm{n}-\pi^{*}$ charge transfer (ILCT) transitions of the aromatic rings and imine and thiocyanate groups. The band at 384 and $351 \mathrm{~nm}$ for 3 and 4, respectively, could be asssigned to the $n-\pi^{*}$ transition of the non-bonding electrons of the sulfur of the isothiocyanate moiety [78]. The absorption bands observed in the visible region (472 and $446 \mathrm{~nm}$, Table 3) were typical of the ligand-to-metal charge transfer (LMCT) transitions of phenolato and pseudohalido ligands to the iron(III) metal center [79,80]. Moreover, the band at $514 \mathrm{~nm}$ for 3 and at $538 \mathrm{~nm}$ for $\mathbf{4}$ could be indicative of high-spin species [55,81]. 

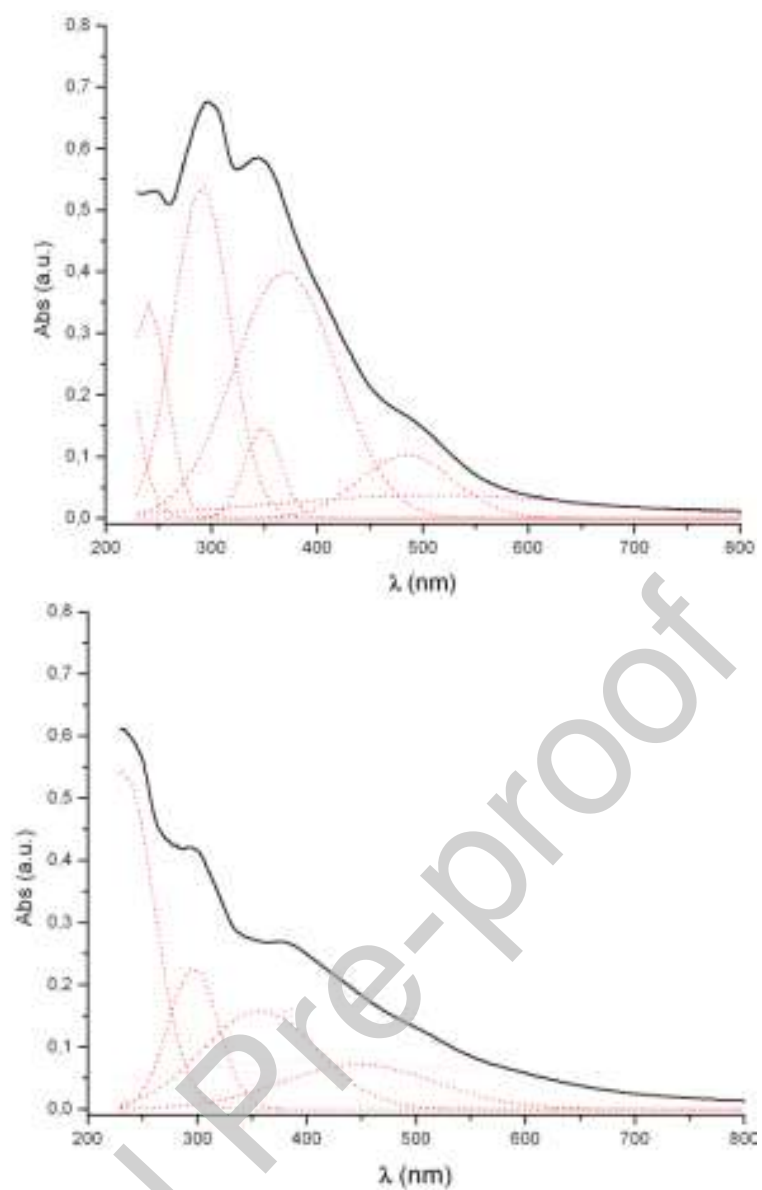

Fig. 5 Experimental UV-vis spectra of complexes 3 (top, full line) and 4 (bottom, full line) recorded in $\mathrm{CH}_{2} \mathrm{Cl}_{2}$ at $20^{\circ} \mathrm{C}$, along with their respective deconvoluted spectra (red dotted lines).

Table 3 Deconvoluted UV-vis. absorption data for complexes 3 and 4.

\begin{tabular}{ccc}
\hline Compd. & $\lambda / \mathrm{nm}$ & Log $\varepsilon$ \\
\hline \multirow{3}{*}{$\mathbf{3}$} & 248 & 4.07 \\
& 295 & 4.26 \\
& 342 & 4.07 \\
& 384 & 4.02 \\
& 472 & 3.62 \\
& 514 & 3.08 \\
\hline \multirow{4}{*}{$\mathbf{4}$} & 296 & 3.87 \\
& 351 & 3.81 \\
& 446 & 3.53 \\
& 538 & 3.17
\end{tabular}




\subsection{Magnetic properties}

The thermal variation of the molar magnetic susceptibility, $\chi_{\mathrm{M}}$, has been measured for a powdered sample of compound 3 (Fig. 6) At room temperature ( $300 \mathrm{~K}$ ), $\chi_{\mathrm{M}} \mathrm{T}$ is equal to $4.13 \mathrm{~cm}^{3}$ $\mathrm{K} \mathrm{mol}^{-1}$ that is very close to the expected value $\left(4.375 \mathrm{~cm}^{3} \mathrm{~K} \mathrm{~mol}^{-1}\right)$ for high spin iron(III) $(\mathrm{S}=5 / 2)$ with $\mathrm{g}=2.00 . \chi_{\mathrm{M}} \mathrm{T}$ remains quasi constant on cooling down to $50 \mathrm{~K}$ then drops more and more rapidly to reach $0.97 \mathrm{~cm}^{3} \mathrm{~K} \mathrm{~mol}^{-1}$ at $2 \mathrm{~K}$. Clearly, such a decrease cannot only be due to local magnetic anisotropy (zero-field splitting) of high spin iron(III) center for which low temperature limit of $\chi_{\mathrm{M}} \mathrm{T}$ should not be lower than $2.5 \mathrm{~cm}^{3} \mathrm{~K} \mathrm{~mol}^{-1}$ [82]. One should in fact consider the combined effect of local anisotropy and intermolecular antiferromagnetic interactions to explain the low temperature decrease. In the absence of crystallographic structure for 4 we have not envisaged to measure magnetic properties to not over interpret the results.

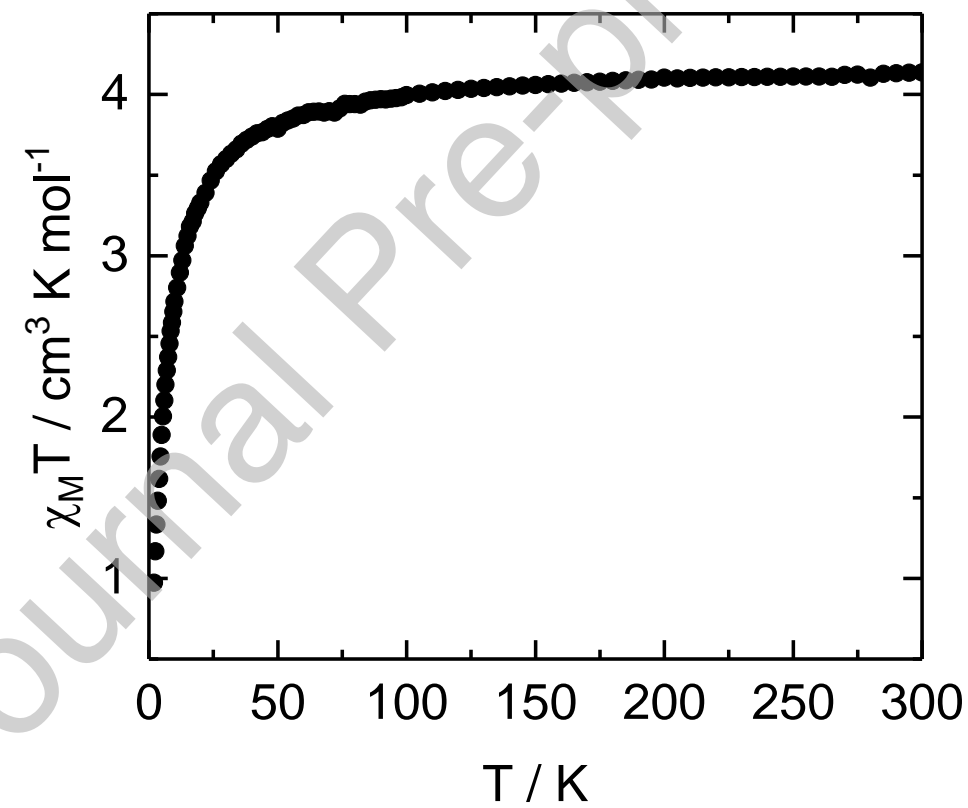

Fig. 6 Thermal variation of $\chi_{M} \mathrm{~T}$ for compound 3 measured at $2 \mathrm{k} \emptyset \mathrm{e}$ below $20 \mathrm{~K}$ and $10 \mathrm{kOe}$ above.

\section{Conclusions}

In summary, we have successfully synthesized and characterized two novel neutral pentacoordinated isothiocyanate iron(III) mixed ligand complexes, $\left[\mathrm{Fe}\left(\mathrm{L}^{\mathrm{A}}\right)(\mathrm{NCS})\right]$ and $\left[\mathrm{Fe}\left(\mathrm{L}^{\mathrm{D}}\right)(\mathrm{NCS})\right]$, where $\mathrm{L}^{\mathrm{A}}$ and $\mathrm{L}^{\mathrm{D}}$ are dianionic $\mathrm{N}_{2} \mathrm{O}_{2}$-tetradentate Schiff-base ligands 
unsymmetrically substituted by either a pair of acceptor or donor groups, respectively. In the two A-- $\pi$-A' and D- $\pi$-D' compounds, the two acceptor or donor units are connected through the conjugated iron(III)-centered macroacyclic Schiff-base core. The stretching frequencies of the thiocyanate group observed at respectively 2014 and $2062 \mathrm{~cm}^{-1}$, in their infrared spectrum, clearly testify a N-bonded coordination mode of the $\mathrm{NCS}^{-}$moiety isothiocyanate isomer in both compounds. This trend agrees with previous results showing that first-row transition metals bond to the thiocyanate ligand through the M-NCS fashion and can be explained using the hard-soft acid-base concepts. The crystal structure of the $\left[\mathrm{Fe}\left(\mathrm{L}^{\mathrm{A}}\right)(\mathrm{NCS})\right]$ derivative was elucidated by $\mathrm{X}$ ray diffraction using single cristal, confirming both the $\mathrm{N}$-coordinated isothiocyanato co-ligand and that the iron(III) ion achieves a square pyramidal geometry. The $\mathrm{N}$ and $\mathrm{O}$ atoms of the Schiff base ligand occupy the basal sites and the nitrogen atom of the isothiocyanate co-ligand is located at the apex of the pyramid. Solid-phase magnetic measurements established the high-spin state (S $=5 / 2$ ) of this $d^{5} \mathrm{Fe}(\mathrm{III})$ complex. Intermolecular interactions were studied by Hirshfeld surface analysis that shows significant $\mathrm{C}-\mathrm{H} \cdots \mathrm{C}, \mathrm{C}-\mathrm{H} \cdots \mathrm{N}$ and $\mathrm{C}-\mathrm{H} \cdots \mathrm{O}$, hydrogen bonds and also weaker $\mathrm{C} \cdots \mathrm{C}$ (of $\pi \cdots \pi$ type) interactions. Further, the reported complexes and related ones that offer great flexibility could be envisioned to build up fascinating supramolecular networks or to functionalize metal nanoparticles or surfaces.

\section{Credit authorship contribution statement}

J. Cisterna: investigation, Software, Writing - original draft. V. Artiguas and M. Fuentealba: crystallography. C. Manzur: Conceptualization, Methodology, Validation, Writing - review \& editing. J.-R. Hamon: Formal analysis, Data curation, Writing - original draft, Writing - review \& editing. D. Carrillo: Conceptualization, Methodology, Validation, Resources, Supervision, Project administration

\section{Declaration of Competing Interest}

The authors declare that they have no known competing financial interests or personal relationships that could have appeared to influence the work reported in this paper.

\section{Acknowledgements}


The authors thank Dr. O. Cador (ISCR Rennes) for determining the magnetic properties, F. Lambert and P. Jehan (CRMPO, Rennes) for helpful assistance with HRMS. This research has been performed as part of the Chilean-French International Research Program "Multifunctional Molecules and Materials" (IRP M3-CNRS No. 1207). Financial support from the Fondo Nacional de Desarrollo Científico y Tecnológico [FONDECYT (Chile), grants no. 1130105 (D.C., C.M. and M.F.) and 1190034 (D.C. and C.M.), the Vicerrectoría de Investigación y Estudios Avanzados, Pontificia Universidad Católica de Valparaíso, Chile (D.C., C.M. and M.F.), the CNRS and the Université de Rennes 1 (France) is gratefully acknowledged. J.C. thanks the CONICYT (Chile) for support of a graduate fellowship and Universidad de Antofagasta for postdoctoral fellowship.

\section{Appendix A. Supplementary material}

CCDC 2042843 contains the supplementary crystallographic data for this paper. These data can be obtained free of charge via www.ccdc.cam.ac.uk/data_request/cif, by e-mailing (data_request@ccdc.cam.ac.uk), or by contacting The Cambridge Crystallographic Data Centre 12 Union Road Cambridge CB2 1EZ, UK. Fax: p44(0)1223-336033.

\section{Appendix B. Supplementary data}

Supplementary data to this article can be found online at https://doi.org/xxx

\section{References}

[1] P.A. Vigato, S. Tamburini, The challenge of cyclic and acyclic schiff bases and related derivatives, Coord. Chem. Rev. 248 (2004) 1717-2128.

[2] M. Karmakar, S. Chattopadhyay, A comprehensive overview of the orientation of tetradentate $\mathrm{N}_{2} \mathrm{O}_{2}$ donor Schiff base ligands in octahedral complexes of trivalent $3 \mathrm{~d}$ metals, J. Mol. Struct. 1186 (2019) 155-186.

[3] C. Camp, L. Chatelain, V. Mougel, J. Pécaut, M. Mazzanti, Ferrocene-Based Tetradentate Schiff Bases as Supporting ligands in Uranium Chemistry, Inorg. Chem. 54 (2015) 57745783. 
[4] K.T. Hylland, S. Øien-Ødegaard, R.H. Heyn, M. Tilset, Zinc Schiff Base Complexes Derived from 2,2'-Diaminobiphenyls: Solution Behavior and Reactivity towards Nitrogen Bases, Eur. J. Inorg. Chem. (2020) 3627-3643.

[5] X. Liu, J.-R. Hamon, Recent developments in penta-, hexa- and heptadentate Schiff base ligands and their metal complexes, Coord. Chem. Rev. 389 (2019) 94-118.

[6] K. Brodowska, E. Łodyga-Chruscinska, Schiff bases: Interesting range of applications in various fields of science, Chemik 68 (2014) 129-134.

[7] O. Santoro, X. Zhang, C. Redshaw, Synthesis of Biodegradable Polymers: A Review on the Use of Schiff-Base Metal Complexes as Catalysts for the Ring Opening Polymerization (ROP) of Cyclic Esters, Catalysts 10 (2020) 800.

[8] P. Das, W. Linert, Schiff base-derived homogeneous and heterogeneous palladium catalysts for the Suzuki-Miyaura reaction, Coord. Chem. Rev. 311 (2016) 1-23.

[9] A. Mondal, S.-Q. Wu, O. Sato, S. Konar, Effect of Axial Ligands on Easy-Axis Anisotropy and Field-Induced Slow Magnetic Relaxation in Heptacoordinated $\mathrm{Fe}^{\mathrm{II}}$ Complexes, Chem. Eur. J. 26 (2020) 4780-4789.

[10] C. Rajnák, J. Titiš, J. Moncol, D. Valigura, R. Boča, Effect of the Distant Substituent to Slow Magnetic Relaxation of Pentacoordinate Fe(III) Complexes, Inorg. Chem. 59 (2020) 14871-14878.

[11] S. Di Bella, A. Colombo, C. Dragonetti, S. Righetto, D. Roberto, Zinc(II) as a Versatile Template for Efficient Dipolar and Octupolar Second-Order Nonlinear Optical Molecular Materials, Inorganics 6 (2018) 133.

[12] L. Rigamonti, A. Forni, E. Cariati, G. Malavasi, A. Pasini, Solid-State Nonlinear Optical Properties of Mononuclear Copper(II) Complexes with Chiral Tridentate and Tetradentate Schiff Base Ligands, Materials 12 (2019) 3595.

[13] S. Celedón, T. Roisnel, V. Artigas, M. Fuentealba, D. Carrillo, I. Ledoux-Rak, J.-R. Hamon, C. Manzur, Palladium (II) complexes of tetradentate donor-acceptor Schiff base ligands: synthesis, spectral, structural, thermal and NLO properties, New J. Chem. 44 (2020) 91909201. 
[14] S. Arulmurugan, H.P. Kavitha, B.R. Venkatraman, Biological activities of Schiff base and its complexes: A review, Rasayan J. Chem. 3 (2010) 385-410.

[15] M.S. Hossain, P.K. Roy, C. Zakaria, M. Kudrat-E-Zahan, Selected Schiff base coordination complexes and their microbial application: a review, Int. J. Chem. Sci. 6 (2018) 19-31.

[16] A. de Fátima, C. de Paula Pereira, C. Raquel Said Dau Gonçalves Olímpio, B. Germano de Freitas Oliveira, L. Lopardi Franco, P. Henrique Corrêa da Silva, Schiff bases and their metal complexes as urease inhibitors - A brief review, J. Adv. Res. 13 (2018) 113-126.

[17] I. Mondal, S. Chattopadhyay, Development of multi-metallic complexes using metal-salen complexes as building blocks, J. Coord. Chem. 72 (2019) 3183-3209.

[18] C. Freire, M. Nunes, C. Pereira, D.M. Fernandes, A.F. Peixoto, M. Rocha, Metallo(salen) complexes as versatile building blocks for the fabrication of molecular materials and devices with tuned properties, Coord. Chem. Rev. 394 (2019) 104-134.

[19] S. Chatterjee, D. Sukul, P. Banerjee, J. Adhikary, Phenoxazinone synthase activity of two iron(III) complexes comprising the same Schiff base ligand: Biomimetic functional model and mechanistic investigation, Inorg. Chim. Acta 474 (2018) 105-112.

[20] S. Roy, T. Dutta, M.G.B. Drew, S. Chattopadhyay, Phenoxazinone synthase mimicking activity of a dinuclear copper(II) complex with a half salen type Schiff base ligand, Polyhedron 178 (2020) 114311.

[21] T.S. Lange, K.K. Kim, R.K. Singh, R.M. Strongin, C.K. McCourt, L. Brard, Iron(III)Salophene: An Organometallic Compound with Selective Cytotoxic and Anti-Proliferative Properties in Platinum-Resistant Ovarian Cancer Cells, PLoS ONE 3 (2008) e2303.

[22] U. Basu, I. Pant, A. Hussain, P. Kondaiah, A.R. Chakravarty, Iron(III) Complexes of a Pyridoxal Schiff Base for Enhanced Cellular Uptake with Selectivity and Remarkable Photocytotoxicity, Inorg. Chem. 54 (2015) 3748-3758.

[23] S. El Deeb, B.N. Ma, D. Baecker, R. Gust, Studies on the stability of the anticancer-active [N,N'-bis(salicylidene)-1,2-phenylenediamine]chloridoiron(III) complex under pharmacological-like conditions, Inorg. Chim. Acta 487 (2019) 76-80. 
[24] E. Mesbahi, M. Bagherzadeh, M. Amini, A. Akbari, A. Ellern, L.K. Woo, A novel binuclear iron(III)-salicylaldazine complex; synthesis, X-ray structure and catalytic activity in sulfide oxidation, Polyhedron 183 (2020) 114531.

[25] W. Zhou, L. Yang, F.-Y. Zhou, Q.-W. Deng, X. Wang, D. Zhai, G.-Q. Ren, K.-L. Han, W.Q. Deng, L. Sun, Salen-Based Conjugated Microporous Polymers for Efficient Oxygen Evolution Reaction, Chem. Eur. J. 26 (2020) 7720-7726.

[26] A.W. Nichols, S. Chatterjee, M.c. Sabat, C.W. Machan, Electrocatalytic Reduction of $\mathrm{CO}_{2}$ to Formate by an Iron Schiff Base Complex, Inorg. Chem. 57 (2018) 2111-2121.

[27] L. Pogny, B. Brachnakov, J. Moncol, J. Pavlik, I. Nemec, Z. Truncek, M. Mazfflr, L. Bucinsky, L. Suchnek, I. Salitros, Impact of Substituent Variation on the Presence of Thermal Spin Crossover in a Series of Mononuclear Iron(III) Schiff Base Complexes with Terminal Pseudohalido Co-ligands, Chem. Eur. J. 24 (2018) 5191-5203.

[28] K. Senthil Kumar, Y. Bayeh, T. Gebretsadik, F. Elemo, M. Gebrezgiabher, M. Thomas, M. Ruben, Spin-crossover in iron(II)-Schiff base complexes, Dalton Trans. 48 (2019) 1532115337.

[29] P.N. Martinho, F.F. Martins, N.A.G. Bandeira, M.J. Calhorda, Spin Crossover in 3D Metal Centers Binding Halide-Containing Ligands: Magnetism, Structure and Computational Studies, Sustainability 12 (2020) 2512.

[30] S. Schönfeld, K. Dankhoff, D. Baabe, M.-K. Zaretzke, M. Bröring, K. Schötz, A. Köhler, G. Hörner, B. Weber, Iron(II) Spin Crossover Complexes Based on a Redox Active Equatorial Schiff-Base-Like Ligand, Inorg. Chem. 59 (2020) 8320-8333.

[31] M. Gerloch, J. Lewis, F.E. Mabbs, A. Richards, The Preparation and Magnetic Properties of Some Schiff Base-Iron(III) Halide Complexes, J. Chem. Soc. A (1968) 112-116.

[32] C.R. Bhattacharjee, P. Goswami, P. Mondal, Synthesis, reactivity, thermal, electrochemical and magnetic studies on Iron(III) complexes of tetradentate Schiff base ligands, Inorg. Chim. Acta 387 (2012) 86-92.

[33] S. Jana, S. Chatterjee, S. Chattopadhyay, Syntheses, characterization and X-ray crystal structures of hexa-coordinated monomeric and oxo-bridged dimeric Fe(III) compounds with salen-type Schiff bases, Polyhedron 48 (2012) 189-198. 
[34] Z. Shaghaghi, R. Bikas, H. Tajdar, A. Kozakiewicz, Iron(III) complexes with $\mathrm{N}_{2} \mathrm{O}_{2}$-donor salophen and azide ligands: Crystal structure, experimental and theoretical studies, J. Mol. Struct. 1217 (2020) 128431.

[35] J. Burmeister, Ambidentate ligands, the schizophrenics of coordination chemistry, Coord. Chem. Rev. 105 (1990) 77-133.

[36] R.G. Pearson, Hard and soft acids and bases: the evolution of a chemical concept, Coord. Chem. Rev. 100 (1990) 403-425.

[37] A. Turco, C. Pecile, Co-ordination of the Thiocyanate Group in Inorganic Compounds, Nature 191 (1961) 66-67.

[38] C. Baer, J. Pike, Infrared Spectroscopic Analysis of Linkage Isomerism in MetalThiocyanate Complexes, J. Chem. Educ. 87 (2010) 724-726.

[39] S. Roy, K. Harms, S. Chattopadhyay, Synthesis, characterization and photocatalytic activity of a dinuclear thiocyanate bridged cadmium(II) Schiff base complex, Polyhedron 127 (2017) 471-477.

[40] S. Khan, S. Sproules, L.S. Natrajan, K. Harms, S. Chattopadhyay, End-on cyanate or end-toend thiocyanate bridged dinuclear copper(II) complexes with a tridentate Schiff base blocking ligand: synthesis, structure and magnetic studies, New J. Chem. 42 (2018) 16341641.

[41] P. Ghorai, P. Brandão, S. Benmansour, C.J. Gómez García, A. Saha, Azido and thiocyanato bridged dinuclear Ni(II) complexes involving 8-aminoquinoline based Schiff base as blocking ligands: Crystal structures, ferromagnetic properties and magneto-structural correlations, Polyhedron 188 (2020) 114708.

[42] L. Li, D. Liao, S. Liu, Z. Jiang, S. Yan, A one-dimensional chain compound [Cu(im2py) $\left.\mathrm{SCN}_{2}\right]_{n}$ exhibiting strong ferromagnetic coupling, Inorg. Chem. Commun. 6 (2003) 225228.

[43] Z.-L. You, catena-Poly[[[N,N''-bis(salicylidene)-propane-1,3-diaminato]cobalt(III)]- $\mu$ azido] and catena-poly[[[N,N''-bis-(salicylidene)propane-1,3-diaminato]-cobalt(III)]- $\mu$ thiocyanato], Acta Crystallogr. Sect. C, 61 (2005) m297. 
[44] C. Donacier Mekuimemba, F. Conan, A.J. Mota, M.A. Palacios, E. Colacio, S. Triki, On the Magnetic Coupling and Spin Crossover Behavior in Complexes Containing the Head-to-Tail $\left[\mathrm{Fe}^{\mathrm{II}}{ }_{2}(\mu-\mathrm{SCN})_{2}\right]$ Bridging Unit: A Magnetostructural Experimental and Theoretical Study, Inorg. Chem. 57 (2018) 2184-2192.

[45] S. Schlamp, J. Schulten, R. Betz, T. Bauch, A.V. Mudring, B. Weber, Synthesis of Anionic Spin Crossover Complexes with Schiff Base like Ligands, Z. Anorg. Allg. Chem. 638 (2012) 1093-1102.

[46] M. Koman, M. Melník, R. Uhrecký, J. Moncol, Crystal structures and Hirshfeld surface analysis of $(\text { cat })_{2}\left[\mathrm{Fe}^{\mathrm{III}}\left(\kappa^{3}\right.\right.$-dipic $\left.)(\mathrm{NCS})_{3}\right]$ and (cat) $\left[\mathrm{Fe}^{\mathrm{III}}\left(\kappa^{3}-\right.\right.$ dipic $\left.)\left(\mathrm{H}_{2} \mathrm{O}\right)(\mathrm{NCS})_{2}\right] \quad($ dipic $=$ dipicolinate), Polyhedron 183 (2020) 114529.

[47] M. Gullotti, L. Casella, A. Pasini, R. Ugo, Optically active complexes of Schiff bases. Part 3. Complexes of iron(III) with quadridentate Schiff bases derived from salicylaldehyde, J. Chem. Soc. Dalton Trans. (1977) 339-345.

[48] W. Chiang, D. Vanengen, M.E. Thompson, Second-Order Non- Linear Optical Properties of Fe(Salen) Complexes, Polyhedron 15 (1996) 2369-2376.

[49] H. Furutachi, A. Ishida, H. Miyasaka, N. Fukita, M. Ohba, H. Koikawa, $\mathrm{Fe}^{\mathrm{II}} \mathrm{Pb}^{\mathrm{II}}$ and $\mathrm{Fe}^{\mathrm{III}}$ complexes of macrocyclic compartmental ligands: different cyclization in stepwise template synthesis using $\mathrm{Fe}^{\mathrm{II}} / \mathrm{Pb}^{\mathrm{II}}$ or Fe $\mathrm{Fe}^{\mathrm{II}} / \mathrm{Pb}^{\mathrm{II}}$ pairs, J. Chem. Soc. Dalton Trans. (1999) 367-372.

[50] C.R. Bhattacharjee, P. Goswami, P. Mondal, Synthesis, structural characterization, and DFT studies of new mixed-ligand iron(III) Schiff-base complexes, J. Coord. Chem. 63 (2010) 2002-2011.

[51] M.V. Nikhil Raj, K. Bhar, S. Jain, M. Rana, T.A. Khan, A.K. Sharma, Syntheses, X-ray structures, electrochemical properties and biological evaluation of mono- and dinuclear $\mathrm{N}_{2} \mathrm{O}_{2}$-donor ligand-Fe systems, Trans. Met. Chem. 44 (2019) 615-626.

[52] A.J. Zare, P. Ataeinia, Synthesis and study of complexes of tetradentate Schiff base and bridging ligand of thiocyanate with transition metals of Fe, Cr and Co, Life Sci. J. 9 (2012) 2396-2405. 
[53] C.R. Mayer, G. Cucchiaro, J. Jullien, F. Dumur, J. Marrot, E. Dumas, F. Sécheresse, Functionalization of Gold Nanoparticles by Iron(III) Complexes Derived from Schiff Base Ligands, Eur. J. Inorg. Chem. (2008) 3614-3623.

[54] D. Astruc, Why is Ferrocene so Exceptional?, Eur. J. Inorg. Chem. (2017) 6-29.

[55] J. Cisterna, V. Artigas, M. Fuentealba, P. Hamon, C. Manzur, J.-R. Hamon, D. Carrillo, Pentacoordinated Chloro-Iron(III) Complexes with Unsymmetrically Substituted $\mathrm{N}_{2} \mathrm{O}_{2}$ Quadridentate Schiff-Base Ligands: Syntheses, Structures, Magnetic and Redox Properties, Inorganics 6 (2018) 5.

[56] M.A. Spackman, P.G. Byrom, A novel definition of a molecule in a crystal, Chem. Phys. Lett. 267 (1997) 215-220.

[57] J.J. McKinnon, A.S. Mitchell, M.A. Spackman, Hirshfeld surfaces: A New Tool for Visualising and Exploring Molecular Crystals, Chem. Eur. J. 4 (1998) 2136-2141.

[58] W.L.F. Armarego, C. Chai. Purification of Laboratory Chemicals, Seventh ed., Elsevier, Ámsterdam, 2012.

[59] G.A. Bain, J.F. Berry, Diamagnetic Corrections and Pascal's Constants, J. Chem. Educ. 85 (2008) 532-536.

[60] APEX3 Package, APEX3, SAINT and SADABS (2016) Bruker AXS Inc., Madison, Wisconsin, USA.

[61] G.M. Sheldrick, A short history of SHELX, Acta Crystallogr. Sect. A, 64 (2008) 112-122.

[62] O.V. Dolomanov, L.J. Bourhis, R.J. Gildea, J.A.K. Howard, H. Puschmann, OLEX2: a complete structure solution, refinement and analysis program. J. Appl. Crystallogr. 42 (2009) 339-341.

[63] J.-S. Jiang, A.T. Brünger, Protein Hydration Observed by X-ray Diffraction, J. Mol. Biol. 243 (1994) 100-115.

[64] P. van der Sluis, A.L. Spek, BYPASS: an effective method for the refinement of crystal structures containing disordered solvent regions, Acta Crystallogr. Sect. A, 46 (1990) 194201. 
[65] M.J. Turner, J.J. McKinnon, S.K. Wolff, D.J. Gromwood, P.R. Spackman, D. Jayalitaka, M.A. Spackman, Crystal Explorer 17.5,. The University of Western Australia, Perth, WA, Australia, 2017, http://hirshfeldsurface.net.

[66] F.L. Hirshfeld, Bonded-Atom Fragments for Describing Molecular Charge Densities, Theor. Chim. Acta 44 (1977) 129-138.

[67] M.A. Spackman, D. Jayatilaka, Hirshfeld surface analysis, CrystEngComm 11 (2009) 19-32.

[68] M.A. Spackman, J.J. McKinnon, Fingerprinting intermolecular interactions in molecular crystals, CrystEngComm. 4 (2002) 378-392.

[69] A. Parkin, G. Barr, W. Dong, C.J. Gilmore, D. Jayatilaka, J.J. McKinnon, M.A. Spackman, C. C. Wilson, Comparing entire crystal structures: structural genetic fingerprinting, CrystEngComm 9 (2007) 648-652.

[70] A. Bondi, van der Waals Volumes and Radii, J. Phys. Chem. 68 (1964) 441-451.

[71] M.A. Spackman, J.J. McKinnon, D. Jayatilaka, Electrostatic potentials mapped on Hirshfeld surfaces provide direct insight into intermolecular interactions in crystals, CrystEngComm 10 (2008) 377-388.

[72] A.D. Becke, Density-functional thermochemistry. III. The role of exact exchange, J. Chem. Phys. 98 (1993) 5648-5652.

[73] R. Ditchfield, W.J. Hehre, J.A. Pople, Self-Consistent Molecular-Orbital Methods. IX. An Extended Gaussian-Type Basis for Molecular-Orbital Studies of Organic Molecules, J. Chem. Phys. 54 (1971) 724-728.

[74] F.H. Allen, O. Kennard, D.G. Watson, L. Brammer, A.G. Orpen, R. Taylor, Tables of bond lengths determined by X-ray and neutron diffraction. Part 1. Bond lengths in organic compounds, J. Chem. Soc. Perkin Trans. 2 (1987) S1-S19.

[75] J. Cisterna, V. Dorcet, C. Manzur, I. Ledoux-Rak, J.-R. Hamon, D. Carrillo, Synthesis, spectral, electrochemical, crystal structures and nonlinear optical properties of unsymmetrical Ni(II) and Cu(II) Schiff base complexes, Inorg. Chim. Acta 430 (2015) 8290. 
[76] R.A. Bailey, S.L. Kozak, T.W. Michelsen, W.N. Mills, Infrared spectra of complexes of the thiocyanate and related ions, Coord. Chem. Rev. 6 (1971) 407-445.

[77] A.W. Addison, T.N. Rao, J. Reedijk, J. van Rijn, G.C. Verschoor, Synthesis, Structure, and Spectroscopic Properties of Copper(II) Compounds containing Nitrogen-Sulphur Donor Ligands; the Crystal and Molecular Structure of Aqua[1,7-bis(N-methylbenzimidazol-2'-yl)2,6-dithiaheptane]copper(ii) Perchlorate, J. Chem. Soc. Dalton Trans. (1984) 1349-1356.

[78] L.F. Lindoy, Reactions involving metal complexes of sulfur ligands, Coord. Chem. Rev. 4 (1969) 41-71.

[79] P. Masárová, P. Zoufalý, J. Moncol, I. Nemec, J. Pavlik, M. Gembický, Z. Trávníček, R. Boča, I. Šalitroš, Spin crossover and high spin electroneutral mononuclear iron(III) Schiff base complexes involving terminal pseudohalido ligands, New J. Chem. 39 (2015) 508-519.

[80] T. Basak, K. Ghosh, S. Chattopadhyay, Synthesis, characterization and catechol oxidase mimicking activity of two iron(III) schiff base complexes, Polyhedron 146 (2018) 81-92.

[81] N. Matsumoto, K. Kimoto, A. Ohyoshi, Y. Maeda, Synthesis and Characterization of Iron(III) Complexes with Unsymmetrical Quadridentate Schiff Bases, and Spin Equilibrium Behavior in Solution, Bull. Chem. Soc. Jpn. 57 (1984) 3307-3311.

[82] O. Kahn, Molecular Magnetism, VCH, 1993.

\section{Graphical Abstract}

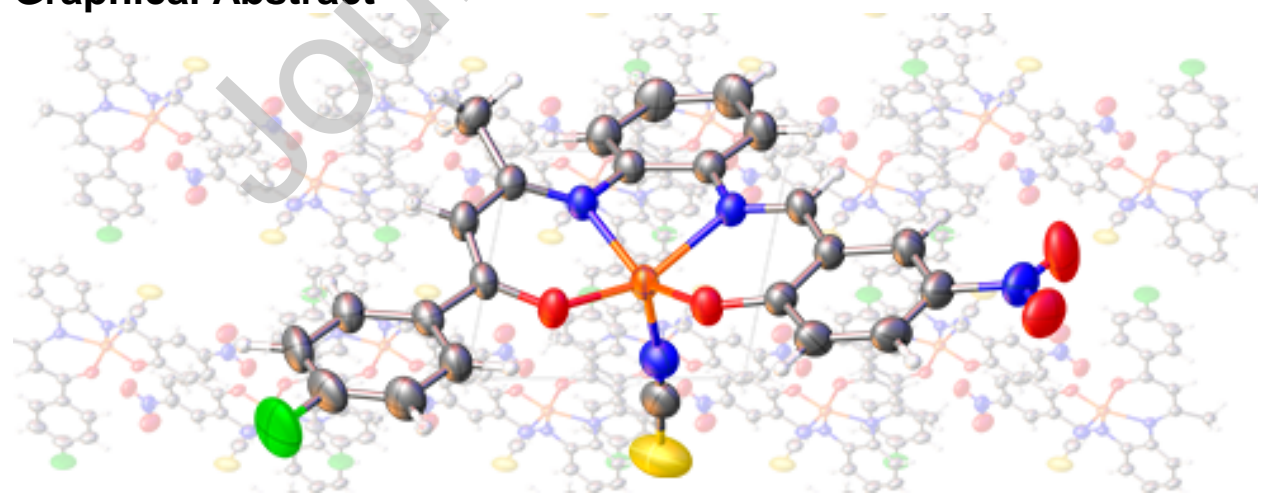

